\title{
Cutaneous Metastatic Disease: Case Series in a Tropical Setting
}

\author{
Maurice E. Asuquo ${ }^{*}$, Aniefon N. Umana², Victor I. C. Nwagbara1, Martin Nnoli ${ }^{3}$, \\ Theophilus Ugbem ${ }^{3}$ \\ ${ }^{1}$ Department of Surgery, University of Calabar, Calabar, Nigeria \\ ${ }^{2}$ Department of Otorhinolaryngology, University of Calabar, Calabar, Nigeria \\ ${ }^{3}$ Department of Pathology, University of Calabar, Calabar, Nigeria \\ Email: *mauefas@yahoo.com, aniefonumana@yahoo.com, aikay_en@yahoo.com, \\ mnnoli@yahoo.com, ugbemti@yahoo.com
}

Received 22 December 2015; accepted 23 January 2016; published 26 January 2016

Copyright (C) 2016 by authors and Scientific Research Publishing Inc.

This work is licensed under the Creative Commons Attribution International License (CC BY). http://creativecommons.org/licenses/by/4.0/

c) (i) Open Access

\begin{abstract}
Background: Cutaneous metastasis is valuable though with infrequent occurrence in clinical practice. It is of esteem value in diagnosis as well as treatment of cancer due to the ease of accessibility for clinical examination and biopsy. Case Series: This is a presentation of 5 consecutive patients with histologic diagnosis of cutaneous metastatic malignancies at the University of Calabar Teaching Hospital, (UCTH), Calabar, Nigeria from 2010 to 2013. They were studied in an attempt to evaluate the clinical significance of cutaneous metastatic nodules/disease in a tropical setting. This was compared with total cutaneous malignancies and total malignancies seen over the same period. Conclusion: The spectrum in the reported cases ranged from localised and barely noticeable nodules to generalised nodules. Clinicians are urged to show renewed interest in cutaneous nodules in view of the estimable value by subjecting such for histological evaluation.
\end{abstract}

\section{Keywords}

Cutaneous Malignancy, Metastatic

\section{Introduction}

Cutaneous metastases arising from carcinomas though rare are important findings in clinical practice [1] [2]. It is reported to occur in $0.7 \%-5 \%$ of cancer patients [3], some have reported up to $9 \%$ [4], and others $10.4 \%$ [5]. In Calabar, the authors setting metastatic skin cancer comprised $6.3 \%$ of total histologically diagnosed skin cancer

${ }^{*}$ Corresponding author.

How to cite this paper: Asuquo, M.E., Umana, A.N., Nwagbara, V.I.C., Nnoli, M. and Ugbem, T. (2016) Cutaneous Metastatic Disease: Case Series in a Tropical Setting. Case Reports in Clinical Medicine, 5, 25-31.

http://dx.doi.org/10.4236/crcm.2016.51005 
[6]. It is relatively uncommon but often a reflection of the presence and course of an internal disease [2] [7]. Cutaneous metastasis is very rare in children and varies according to sex. Metastasis from the colon including lungs is common in males while that from the breast commoner in females [1] [2]. Clinical findings may be barely noticeable and require a high index of suspicion [2]. Skin metastasis presents commonly as skin nodules (single or multiple), usually painless and may mimic dermatofibroma, neurofibroma, lipoma and granuloma [1] [2] [8]. Some malignancies have a predilection for areas of metastasis, which can be useful in directing search for the primary site [2]. Presentation is classified into the following settings: a) develop after initial diagnosis of primary malignancy, b) carcinoma of unknown primary site (CUPS), c) detected as the same time of diagnosis [1] [2]. Diagnosis is based on histology and the pattern provides clue to the location of the primary malignancy [1]. In addition, immunohistochemistry provides a useful adjunct in directing search of the primary tumour [2] [9]. Olfactory neuroblastoma is a rare slow growing malignant tumour that arises from neuroepithelial cells of the olfactory membrane. Scalp metastasis from olfactory neuroblastoma has been described [10]. Treatment is palliative and simple excision is the treatment of choice [2] [3]. We present this study to enkindle the significance of cutaneous metastasis in clinicians and urge for renewed interest.

\section{Case Series}

Case 1

H. I, a 65-year-old male presented with recurrent abdominal pain and swelling of 9 months duration. He noticed recurrent episodes of right sided abdominal pain and admitted to episodes of alternating history of constipation and diarrhea. However, there was no history of passage blood in stool but admitted to history of weight loss and gets tired easily. His attention was drawn to the presence of an umbilical swelling as part of his clinical evaluation 6 months after the onset of his ailment.

Examination revealed a chronic ill-looking patient, anicteric, pale, afebrile with no peripheral lymphadenopathy. Pulse was 76 beats per minute and Blood pressure 140/70 mm/Hg. Chest examination was normal. Abdominal examination revealed no organomegally except for a mild tenderness on palpation of the right flank in addition to an umbilical nodule that was non tender, firm, measuring $2 \times 1.5 \mathrm{~cm}$. Rectal examination was not remarkable. A preoperative diagnosis of colonic cancer was made.

Haemogram showed a packed cell volume (PCV) of $29 \%$, white blood count (WBC) $5.3 \times 10^{9} /$, (lymphocytes $27 \%$, neutrophils $70 \%$, monocytes $2 \%$, and eosinophils $1 \%$ ), Platelets $257 \times 10^{9} / \mathrm{l}$, ESR $80 \mathrm{~mm} / \mathrm{hr}$. Faecal occult blood was positive. Carcino embryonic antigen (CEA) was $7.0 \mathrm{ng} / \mathrm{ml}$. Chest X-Ray (CXR) was normal. Abdominal computerized tomogram (CT) was reported as revealing features suggestive of malignant mass in the ascending colon. Biopsy of the umbilical nodule revealed metastatic adenocarcinoma.

Patient was commenced on haematinics counseled for surgery which he declined and was lost to follow-up after a month.

Case 2

A. E, was a 75-year-old female, she presented with a mass located at the upper part of the back of 4 months duration. She however did not present with any other symptoms.

Examination revealed a patient in apparent good health, anicteric, not pale, afebrile with no peripheral lymphadenopathy. Chest and abdominal examinations were normal. Rectal and vaginal examinations were not remarkable. Examination of the back revealed a hard irregular non tender, cutaneous mass over the left scapula measuring $3.5 \times 2.5 \mathrm{~cm}$.

Haemogram revealed a PCV 34\%, WBC $5.8 \times 10^{9} / 1$, (Neutrophils 70\%, lymphocytes $28 \%$, monocytes $1 \%$, eosinophils $1 \%$ ), platelets $276 \times 10^{9} /$. Biopsy of the mass revealed metastatic adenocarcinoma suggestive of colonic site.

Patient however, declined further evaluation on account of cost and was lost to follow-up after one month.

Case 3

J. T, was a 56-year-old female who presented with multiple swellings on the scar of a previous operation of 3 months duration. She was offered a right hemicolectomy 3 months ago for a diagnosis of carcinoma of the caecum that presented as an emergency with malignant intestinal obstruction.

Examination revealed a patient in relative good health, anicteric, afebrile, not pale with no peripheral lymphadenopathy. Chest examination was normal. Abdominal examination was essentially normal but for 3 discrete nodules distributed along the laparotomy scar. They were non tender, hard with measurements that ranged from $1.5 \times 1.0$ to $1.5 \times 2 \mathrm{~cm}$. Rectal examination was normal. 
Haemogram showed a PCV of 33\%, WBC $5.0 \times 10^{9} / 1$ (Neutrophils 70\%, lymphocytes $26 \%$, monocytes $2 \%$, and eosinophils $2 \%$ ), platelets $272 \times 10^{9} / \mathrm{l}$. CXRay and abdominal ultrasound scan (USS) were reported as normal. CEA was $5.3 \mathrm{ng} / \mathrm{ml}$. Nodules were excised and histology revealed metastatic adenocarcinoma. She was commenced on adjuvant chemotherapy with 5FU but was however lost to follow-up after 2 months.

Case 4

I. S. E, a 37-year-old male barber presented with multiple skin masses located on the fore head, left shoulder, anterior abdominal wall, back, gluteal region and left foot; (Figure 1(a) and Figure 1(b)) of 2 months duration as a referral from the ear, nose and throat (ENT) clinic.

Nine months prior to this he presented to the ENT clinic with a 2 month history of left eye protrusion and left nasal obstruction of 6 months duration. Clinical examination then revealed a chronically ill-looking man with left cervical lymphadenopathy $(3 \times 4 \mathrm{~cm})$ with supraorbital proptosis of the left eye with a firm mass on the medial canthus. Visions in both eyes were intact. CT of the paranasal sinuses showed left orbital mass involving the nasal cavity, ethmoidal, maxillary and sphenoidal sinuses. Histology and immunohistochemistry of the mass revealed-olfactory neuroblastoma

He was offered 3 courses of 5FU, cisplatin and zofran fortnightly and 2 weeks of radiation which initially resulted in near resolution of the mass and nasal obstruction. However, 6 weeks after commencement of chemoradiation, multiple skin masses appeared.

Excision of the masses at the shoulder and anterior abdominal wall revealed metastatic olfactory neuroblastoma (Figure 2(a) and Figure 2(b)). He succumbed to the metastatic disease within 11months of onset of the illness and 2 months of the development of cutaneous metastases.

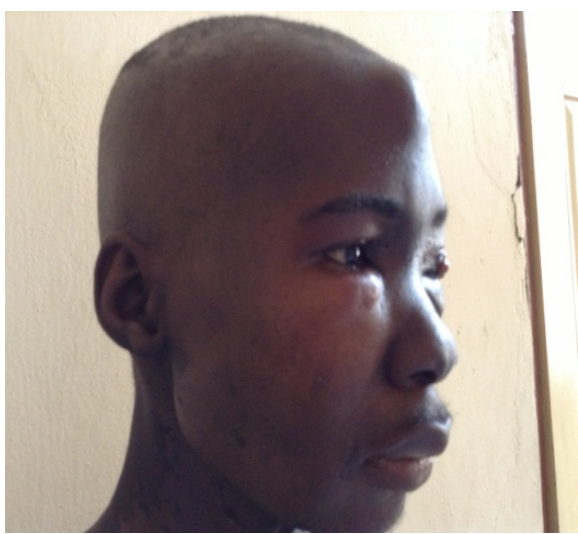

(a)

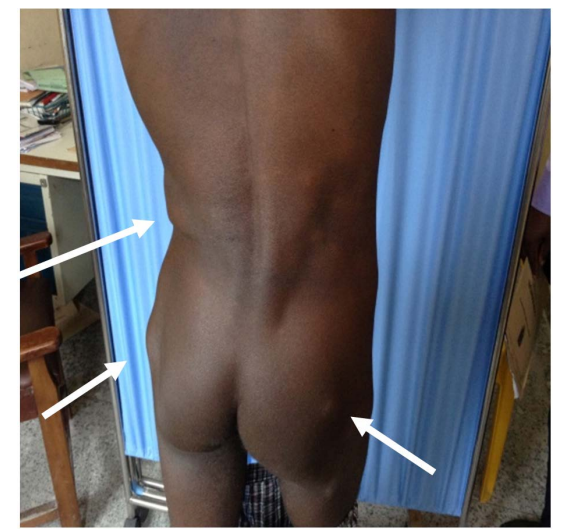

(b)

Figure 1. (a) Clinical Photograph-Showing metastatic nodule forehead, (b) clinical photograph showing metastatic nodules on the left side of the back and buttocks.

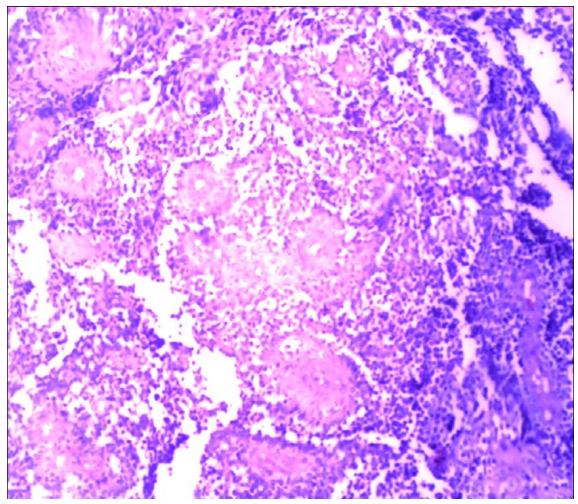

(a)

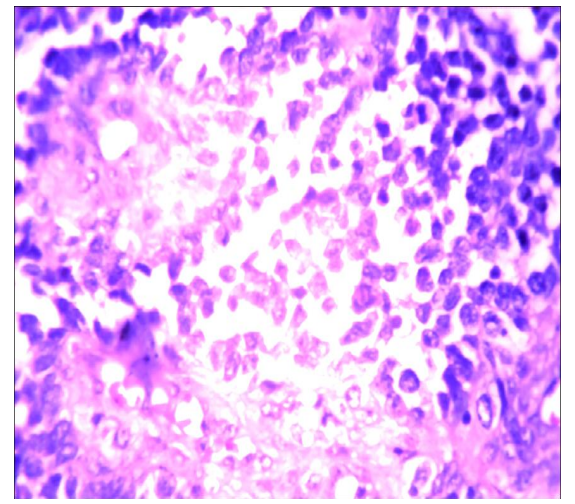

(b)

Figure 2. (a) Photomicrograph H \& E $\times 40$ metastatic olfactory neuroblastoma, (b) photomicrograph $\mathrm{H} \& \mathrm{E} \times 100$ metastatic olfactory neuroblastoma. 
Case 5

H. E, a 60-year-old retired female civil servant who presented to the surgical outpatient department (SOPD) as a referral from the General Hospital in Calabar with a 5 month history of abdominal pain and progressive abdominal distension of 4 months duration following umbilical herniorrhaphy. She reported to have had a painless reducible umbilical swelling since childhood that became painful and irreducible and was offered herniorrhaphy, Figure 3. The post operative period was reported as uneventful; however, 4 weeks after surgery, she developed above presenting complaints. Pain initially located in the epigastrium was burning and radiated to both flanks. It later became colicky slightly relieved by lying on her sides. There was associated non bilious vomiting, intermittent constipation and passage of pelletized faeces with periods of dark tarry stool.

She was not a known peptic ulcer disease patient, known hypertensive and non diabetic but admitted to loss of weight. She was commenced on anti Kock's therapy to no avail prior to referral. The onset of increasing dyspnoea, abdominal swelling and pedal oedema necessitated her referral.

Examination revealed acute-on-chronic ill looking patient in respiratory distress, anicteric, pale, afebrile with bilateral pitting oedema and no peripheral lymphadenopathy. Respiratory rate was 30 cycles/min. Pulse rate was 92 beats/min, BP 160/90 mm/Hg. Abdominal examination revealed a grossly distended abdomen that moved with respiration. There was a transverse scar across the umbilicus with 2 Sister Mary Joseph's nodules, Figure 3. Organs were not ballotable due to gross ascites. Vaginal and digital rectal examinations were unremarkable. A diagnosis of metastatic colonic cancer was made.

Full blood count showed, PCV 32\%, WBC $4.5 \times 10^{9} /$ (lymphocytes 24\%, neutrophils 72\%, monocytes 4\%), platelets $252 \times 10^{9} / \mathrm{l}$, ESR $90 \mathrm{~mm} / \mathrm{hr}$. CXRay revealed features of hypertensive heart disease. Abdominal CT showed features in keeping with advanced transverse colonic tumour. Histology of umbilical nodule was reported as metastatic poorly differentiated adenocarcinoma, (Figure 4(a) and Figure 4(b)).

She was commenced on antihypertensive drugs, iron dextran and had 2 courses of 5FU. Dyspnoea persisted despite 2 episodes of abdominal paracentesis an succumbed to metastatic disease 5 months post appearance of the umbilical nodule.

\section{Discussion}

Cutaneous metastasis from primary internal malignancies is uncommon. The total number of cutaneous malignancy that presented in the authors setting (2010-2013) was 60 [55(92\%) primary, while 5(8\%) were metastatic], and total cutaneous malignancy accounted $10 \%$ of total malignancies during the same study period, Table 1. The 5(8\%) consecutive patients presented accounted for $0.8 \%$ of total malignancies. Aksoy S et al. reported a frequency of cutaneous metastasis that ranged between $0.7 \%$ and $10.4 \%$ of all patients with malignancies [11]. This compares favourably with this report $(0.8 \%)$ and our earlier report in which cutaneous metastasis accounted for $6.5 \%$ of total cutaneous cancer and $0.65 \%$ of total malignancy [1]. Virtually every cancer can present with cutaneous metastasis, however some do so more often than others do. The most frequent non-cutaneous tumours associated with skin metastasis are breast, lung, colorectal [11]. This study revealed the colon as the commonest

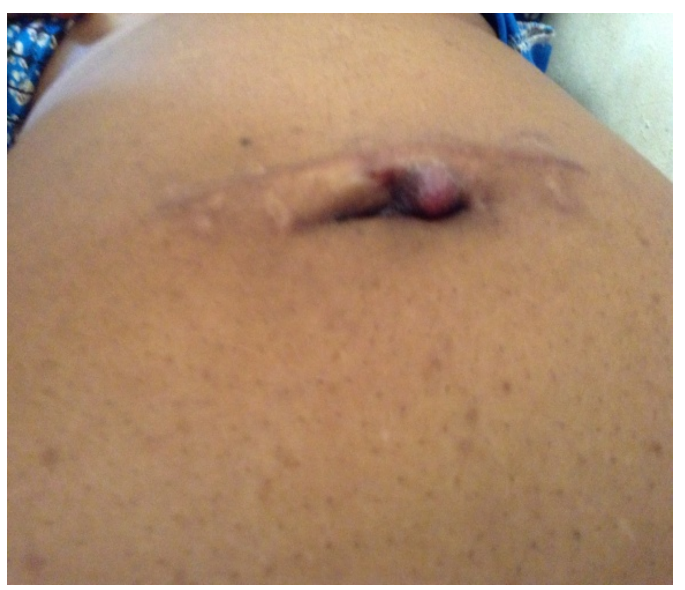

Figure 3. Clinical photograph showing umbilical nodules and previous (umbilical herniorrhaphy). 


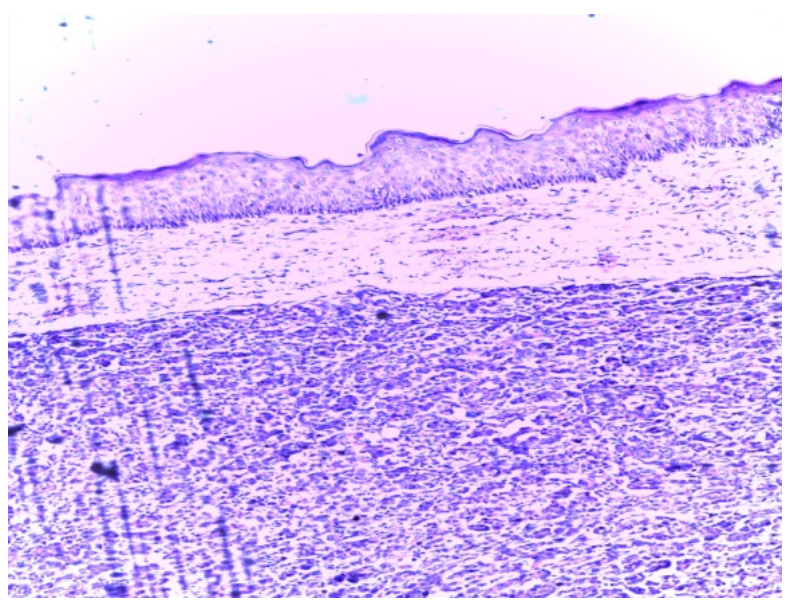

(a)

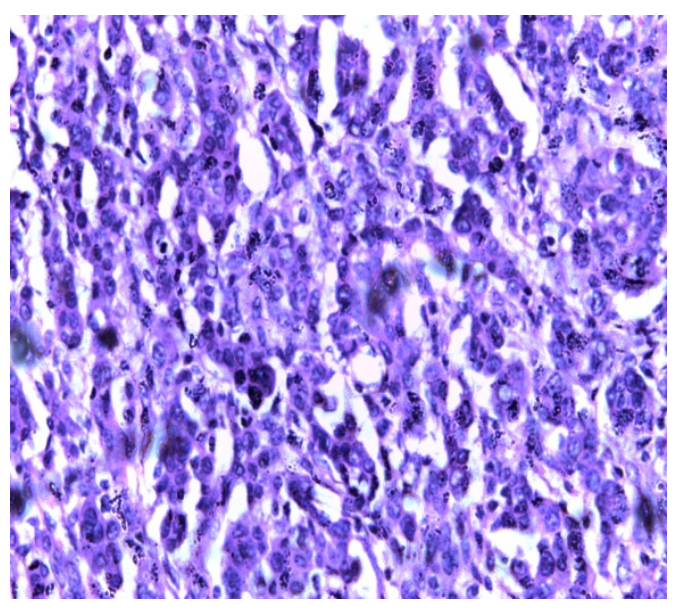

(b)

Figure 4. (a) Photomicrograph H \& E $\times 40$ metastatic adenocarcinoma, (b) photomicrograph H \& $\mathrm{E} \times 100$ metastatic adenocarcinoma.

Table 1. Summary of clinicopathological features (2010-2013).

\begin{tabular}{|c|c|c|c|c|c|c|}
\hline $\mathrm{S} / \mathrm{N}$ & Age & Sex & $\begin{array}{l}\text { Clinical presentation } \\
\text { (Diagnosis) }\end{array}$ & $\begin{array}{l}\text { Site of } \\
\text { cutaneous nodule }\end{array}$ & Histology & Remarks \\
\hline 1. & 68 & $\mathrm{M}$ & $\begin{array}{l}\text { Recurrent large bowel } \\
\text { adenocarcinoma } \\
\text { (ascending colon) }\end{array}$ & Umbilicus & $\begin{array}{l}\text { Metastatic } \\
\text { adenocarcinoma }\end{array}$ & $\begin{array}{l}\text { Refused } \\
\text { surgery. Lost to } \\
\text { follow up }\end{array}$ \\
\hline 2. & 75 & $\mathrm{~F}$ & Irregular hard cutaneous mass & Left scapula region & Metastatic adenocarcinoma & Lost to follow up \\
\hline 3. & 56 & $\mathrm{~F}$ & $\begin{array}{l}\text { Multiple nodules scar } \\
\text { of previous laparotomy }\end{array}$ & $\begin{array}{l}\text { Anterior abdominal } \\
\text { wall (midline scar) }\end{array}$ & $\begin{array}{l}\text { Metastatic } \\
\text { adenocarcinoma }\end{array}$ & $\begin{array}{l}\text { Adjuvant } \\
\text { chemotherapy } \\
\text { 5FU. Lost to } \\
\text { follow up }\end{array}$ \\
\hline 4. & 37 & M & $\begin{array}{l}\text { Multiple cutaneous masses } \\
\text { Figure } 1\end{array}$ & $\begin{array}{l}\text { Fore head, abdomen } \\
\text { back gluteal, left foot }\end{array}$ & $\begin{array}{l}\text { Metastatic olfactory } \\
\text { neuroblastoma } \\
\text { Figure 2(a) and Figure 2(b) }\end{array}$ & $\begin{array}{l}\text { Mortality. } 2 \\
\text { months } \\
\text { (post cutaneous } \\
\text { nodules) }\end{array}$ \\
\hline 5. & 60 & $\mathrm{~F}$ & $\begin{array}{l}\text { Abdominal distension } \\
\text { umbilical nodules } \\
\text { Figure } 3\end{array}$ & Umbilicus & $\begin{array}{l}\text { Metastatic adenocarcinoma } \\
\text { Figure 4(a) and Figure 4(b) }\end{array}$ & $\begin{array}{l}\text { Hospital mortality } \\
5 \text { months (post } \\
\text { cutaneous nodules) }\end{array}$ \\
\hline
\end{tabular}

Total cutaneous malignancy 60 (55 (92\%)—primary, 5 (8\%)—Metastatic). Total cutaneous malignant 10\% of total malignancy. Total cutaneous metastatic malignant $-0.8 \%$ of total malignancy.

primary site for cutaneous metastasis in these series in our setting. Cutaneous metastases from abdominal cancers are uncommon occurring in less than $5 \%$ of patients [12].

Cutaneous metastases are detached extensions of primary tumours to the skin. Four metastatic pathways namely regional spread (through body cavities), transplantation (via surgery or other invasive procedures), lymphatic (common for carcinomas), and haematogenous (common for sarcomas) have been documented [2]. In keeping with these pathways, metastatic sites are usually predictable though unusual sites and wide spread metastases may occur in keeping with our patients with colonic primary sites spreading to the anterior abdominal wall/back and metastatic olfactory neuroblastoma respectively.

Majority of cases present with painless nodules after diagnosis [2]. This was the experience in all our patients. Most cutaneous metastases occur near to the primary as depicted in this study, 2 (40\%) patients presented with Sister Mary Joseph's nodules with primary malignancies in the colon, while another developed nodules on the 
laparotomy scar following right hemicolectomy for carcinoma of the caecum. However, in rare circumstances, (Case 2), cutaneous metastasis may be the only sign of the disease post operative or present as carcinoma of unknown primary site (CUPS), [11].

Cutaneous metastasis may occur at any time in the course of the malignancy and spread may follow, direct extension, lymphogenous, intravascular dissemination or surgical implantation as noted in a patient [4] [11]. Development of extensive cutaneous metastatic disease as demonstrated in the patient with metastatic olfactory neuroblastoma while under treatment with chemotherapy and radiotherapy represents failure of current treatment and possibly an indicator of poor prognosis. A similar phenomenon has been described with gastric carcinoma with cutaneous metastases on the head, neck, axilla, chest and upper limb [13]. Late presentation with attending complications is a common event in our setting. Two (40\%) patients presented with malignant intestinal obstruction with metastatic nodules already manifest.

Diagnosis is by histology and comprehensive evaluation includes assay for markers, imaging, and immunohistochemistry especially when in search for the primary site as in CUPS [2]. Cutaneous lesions may be primary or metastatic, certain features are characteristic of metastatic lesions as depicted in this study. Most of the tumour is found in the deep reticular dermis and subcutaneous Figure 4(b) and neoplastic cells in between collagen bundles. The epidermis is usually not involved, Figure 4(a), except in later stages with direct spread [1] [2] [4]. Metastasis is classified into adenocarcinoma, Figure 4(a) and Figure 4(b), squamous cell carcinoma or undifferentiated (anaplastic). The later require immunohistochemistry to establish the tissue of origin [1].

Treatment is palliative aimed at improving the quality of life especially when indicated by disfigurement or pain. Wide local excision of the cutaneous lesion is recommended. Other modalities include cryotherapy, photodynamic therapy, radiation, intralesional, or topical chemotherapy [1] [2] [10].

The outcomes were generally poor, 2 (40\%) patients were recorded mortalities (5 months and 2 months after diagnosis cutaneous metastases), while others were lost to follow up with advance primary disease. Mortality rate is high; however, some improvement has been recorded with chemotherapy. Overall survival has been reported between 3 - 9 months in keeping with this report [2]. Others have reported median survival of 6.5 months after cutaneous metastasis and 50\% of patients die with 6 months with cutaneous metastasis [14].

Following the increasing incidence of malignancies, dermatologists including dermatopathologists and generally clinicians are likely to encounter cutaneous metastases hitherto regarded as insignificant and are of esteemed value in directing search for the associated primary malignancy [15]. Cutaneous metastatic disease detected in patients in with malignant intestinal obstruction may be an indicator of poor prognosis, [16]. Clinicians are encouraged to search for this and subject skin nodules to pathologic evaluation in view of the treasured value in diagnosis and search for primary malignancies.

\section{Conclusion}

Cutaneous metastasis though not a frequent event shows a pattern of clinical significance hence the request for renewed interest by clinicians. Recognition may be a pointer to an undiagnosed disease and when detected warrant a thorough metastatic work up that may result in accurate staging of the disease. Meticulous surgical techniques can prevent skin metastasis from implantation while wide spread metastases may be an indicator of poor prognosis.

\section{References}

[1] Asuquo, M.E., Umoh, M.S. and Bassey, E.E. (2010) Cutaneous Metastatic Carcinoma: Diagnostic and Therapeutic Values. Advances in Skin \& Wound Care, 23, 77-80. http://dx.doi.org/10.1097/01.ASW.0000363504.92360.5f

[2] Helm, T.N., Lee, T.C., Elston, D.M., Heymann, W.R., Schwartz, R.A. and Wells, M.J. (2014) Dermatologic Manifestation of Metastatic Carcinomas. http://emedicine.medscape.com/article/1101058-overwiew

[3] Nesseris, I., Tsamakis, C., Gregoriou, S., Ditos, I., Christofidou, E. and Rogopoulos, D. (2013) Cutaneous Metastasis of Colon Adenocarcinoma: Case Report and Review of the Literature. Anais Brasileiros de Dermatologia, 88, 556558.

[4] Pereina, W.A., Humaine, C.R., Silia, C.S. and Fermandos, L.H. (2011) Sister Mary Joseph’s Nodule a Sign of Internal Malignancy. Anais Brasileiros de Dermatologia, 86, 118-120. http://dx.doi.org/10.1590/S0365-05962011000700031

[5] Krathen, R.A., Orengo, I.E. and Rosen, T. (2003) Cutaneous Metastasis: A Meta Analysis of Data. Southern Medical Journal, 96, 164-166. http://dx.doi.org/10.1097/01.SMJ.0000053676.73249.E5 
[6] Asuquo, M.E., Ngim, O., Ugare, G., Omotoso, J. and Ebughe, G. (2008) Major Dermatological Malignancies Encountered in a Teaching Hospital Surgical Department in South Nigeria. American Journal of Clinical Dermatology, 9, 383387. http://dx.doi.org/10.2165/0128071-200809060-00004

[7] Asuquo, M.E., Umoh, M.S., Ikpeme, I.A., Otei, O.O., Ebughe, G. and Omotoso, J. (20099) Skin Malignancies in Calabar, Southern Nigeria. Journal Africain du Cancer, 1, 59-63. http://dx.doi.org/10.1007/s12558-009-0030-3

[8] Omranipour, R., Mofrad, H.R.H., Fereidouni, F. and Kalaghchi, B. (2009) Cutaneous Metastasis of Gastrointestinal Cancers. Acta Medica Iranica, 47, 335-338.

[9] Nwagbara, V.I.C., Asuquo, M.E., Bassey, I.A. and Edem, B. (2015) Huge Fistulous Gluteal Mass: A Rare Presentation of Rectal Cancer. Journal Africain du Cancer, 7, 54-56. http://dx.doi.org/10.1007/s12558-014-0345-6

[10] Chew, Y.K., Cheong, J.P., Brito-Mutunaya Gam, S., Khir, A., Prepageran, N. and Mun, K.S. (2011) Subcutaneous Metastasis of Olfactory Neuroblastoma: An Uncommon Presentation. Medical Journal of Malaysia, 66, 62-63.

[11] Kilickap, S., Aksoy, S., Dincer, M., Saglam, E.A. and Yalcin, S. (2006) Cutaneous Metastasis of Signet Cell Carcinoma of the Rectum without Accompanying Visceral Involvement. Southern Medical Journal, 99, 1137-1139. http://dx.doi.org/10.1097/01.smj.0000221633.71021.ac

[12] Tan, K., Ho, K., Lai, J., Lim, J., Ooi, B., Tang, C. and Eu, K. (2006) Cutaneous and Subcutaneous Metastases of Adenocarcinoma of the colon and Rectum. Annals, Academy of Medicine, Singapore, 35, 585-587.

[13] Schwartz, R.A. (1995) Cutaneous Metastatic Disease. Journal of the American Academy of Dermatology, 33, $161-182$.

[14] Schoenlaub, P., Sarraux, A., Grosshans, E., Heid, E. and Cribier, B. (2001) Survival after Cutaneous Metastasis: A Study of 200 Cases. Annales de Dermatologie et de Vénéréologie, 128, 1310-1315.

[15] Sariya, D., Ruth, K., Adams-McDonnell, R., Cusack, C., Xu, X.W., Elenitsis, R., Sey Kora, J., Pasha, T., Zhang, P., Baldassaro, M., Lessin, S.R. and Wu, H. (2007) Clinicopathologic Correlation of Cutaneous Metastasis. Archives of Dermatology, 143, 618-663. http://dx.doi.org/10.1001/archderm.143.5.613

[16] Asuquo, M.E., Inyang, A., Nwagbara, V. and Jibril, P. (2005) Malignant Large Bowel Obstruction. Nigerian Journal of Surgical Sciences, 15, 67-70. 